Volume 5 Oktober, 2020 (117-124)

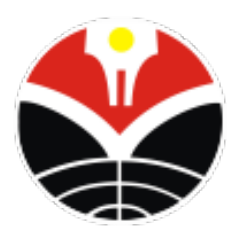

JTIKOR (Jurnal Terapan Ilmu Keolahragaan)

http://eiournal.upi.edu/index.php/JTIKOR

https://doi.org/10.17509/itikor.v5i2.27960

\title{
Hubungan Durasi Tidur dan Perilaku Sedentari dengan Body Mass Index pada Siswa SMA Negeri 3 Ciamis
}

\author{
Krisbi Sara ${ }^{\bowtie}$, Risma, Nana Sutisna \\ Pendidikan Jasmani, Fakultas Keguruan dan Ilmu Pendidikan, Universitas Galuh Ciamis
}

\section{Info Artikel}

\section{Kata Kunci:}

Indeks massa tubuh, durasi tidur, perilaku sedentari,

Keywords:

Body mass index, sleep duration, sedentary behavior,

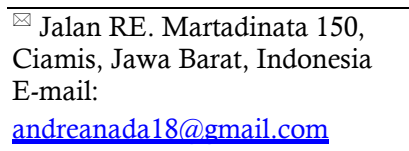

\begin{abstract}
Abstrak
Indonesia seperti negara berkembang lainnya mengalami permasalahan obesitas pada remaja. Ada beberapa faktor yang menjadi penyebab terjdinya obesitas diantaranya adalah durasi tidur dan perilaku sedentari. Penelitian ini bertujuan untuk mengkaji hubungan antara durasi tidur dan perilaku sedentari dengan body mass index pada siswa SMA Negeri 3 Ciamis. Metode yang digunakan pada penelitian ini adalah metode Correlational. Sampel berjumlah 36 orang siswa SMA di Kabupaten Ciamis. Instrumen yang digunakan untuk mengukur durasi tidur dan perilaku sedentari adalah alat ActivPal, sedangkan untuk mengukur body mass index adalah dengan pengukuran tinggi badan dan berat badan siswa. Berdasarkan hasil analisis data, deskripsi, pengujiam hasil penelitian, dan hasil analisis korelasi pearson product moment $\mathrm{rx}_{1} \mathrm{y}=-0,264$, bahwa terdapat hubungan negatif antara durasi tidur dengan body mass index dengan kekuatan sangat rendah. $\mathrm{rx}_{2} \mathrm{y}=0,008$, bahwa terdapat hubungan positif antara perilaku sedentari dengan body mass index dengan kekuatan sangat rendah. Sedangkan hasil analisis regresi linear multiples dengan hasil $\mathrm{rx}_{12} \mathrm{y}=0,339$, bahwa terdapat hubungan antar durasi tidur dan perilaku sedentari dengan body mass index.
\end{abstract}

\section{Abstract}

Indonesia, like other developing countries, has obesity problems in adolescents. There are several factors that cause obesity, including the duration of sleep and sedentary behavior. This study aims to examine the relationship between sleep duration and sedentary behavior with body mass index in high school students 3 Ciamis. The method used in this study is the Correlational method. The sample consisted of 36 high school students in Ciamis Regency. The instrument used to measure sleep duration and sedentary behavior is the ActivPal tool, while to measure body mass index is the measurement of students' height and weight. Based on the results of data analysis, description, testing of research results, and the results of product moment correlation analysis rx1y $=-0.264$, that there is a negative relationship between sleep duration and body mass index with very low strength. $r x 2 y=0.008$, that there is a positive relationship between sedentary behavior with a body mass index with very low strength. While the results of linear multiples regression analysis with the results of $r x 12 y=0.339$, that there is a relationship between sleep duration and sedentary behavior with body mass index.

Copyright (C) 2020, Authors 


\section{PENDAHULUAN}

Kemajuan zaman dan arus globalisasi sangatlah mempengaruhi kehidupan setiap individu di Indonesia maupun di negara-negara lainnya, baik ditinjau dari teknologi maupun gaya hidupnya. Pada era globalisasi ini menyebabkan perubahan perilaku yang menimbulkan ketidakseimbangan dalam melakukan aktivitas fisik. Rendahnya tingkat aktivitas fisik merupakan salah satu faktor peningkatan body mass index (BMI). Seseorang yang secara fisik bugar dapat melakukan aktivitas fisik sehari-hari dengan giat memiliki risiko rendah dalam masalah penyakit obesitas dan dapat menikmati olahraga serta berbagai aktivitas lainnya (Meredith, 1996).

Data hasil dari buku Profil Kesehatan di

Jawa Barat (2017), secara nasional menunjukkan angka status gizi pada anak usia 13-15 tahun terdiri dari, $2 \%$ sangat kurus, $6,5 \%$ kurus, $71,5 \%$ normal 7,5\% gemuk, dan 2,5\% sangat gemuk (obesitas). Sedangkan pada anak umur 16-18 tahun terdiri dari 1,4\% sangat kurus, $7,7 \%$ kurus, $83,3 \%$ normal, $6,2 \%$ gemuk dan $1,4 \%$ sangat gemuk (obesitas) (Dinkes Jabar, 2017). Selain itu masalah yang harus diperhatikan yakni masalah kegemukan. Di Indonesia masalah kegemukan pada anak umur 13-18 tahun masih tinggi. Berdasarkan dari data riset tersebut dapat disimpulkan bahwa angka prevalensi yang mengalami masalah berat badan dibawah angka normal dan berat badan diatas angka normal (obesitas) yang terjadi pada masyarakat di Indonesia terkhusus pada anak Sekolah Menengah Atas membutuhkan perhatian khusus. Apabila masalah tersebut hanya dibiarkan tanpa adanya tindakan pencegahan sejak dini dapat menjadi salah satu permasalahan yang cukup serius di masa yang akan datang. Salah satu cara untuk menekan dan menghambat angka obesitas yang terjadi sejak dini adalah rutin melakukan aktivitas fisik. Tetapi, pada era sekarang intensitas aktivitas fisik telah mengalami penurunan.

Anak-anak dan remaja kini lebih banyak menghabiskan waktu mereka dengan dengan menonton televisi dan bermain game. Tren perilaku seperti itu disebut dengan perilaku sedentari. Perilaku sedentari adalah segala macam aktivitas diluar waktu tidur, dalam posisi duduk atau berbaring yang tidak memerlukan banyak energi atau bahkan sangat sedikit (Tremblay,2012). Di Kanada, anak-anak dan remaja rata-rata menghabiskan waktunya dengan perilaku sedentary lebih dari 6 jam dalam sehari (Colley et al, 2011). Data World Health Organization menyatakan bahwa salah satu faktor terjadinya obesitas anak adalah meningkatnya perilaku sedentari dan kurangnya aktivitas fisik (Paramitha, 2013).

Berdasarkan hasil Profil Kesehatan di Jawa Barat (2017), menunjukkan angka sebesar 33.5 masyarakat di Indonesia usia $\geq 10$ tahun yang tergolong kurang aktif. Semakin menurunnya tingkat aktivitas fisik pada anak dan diikuti kurang tepatnya pola makan, mempunyai peluang peningkatan body mass index (BMI) secara terus-menerus. Sebaliknya apabila melakukan aktivitas fisik secara berlebihan dan asupan yang dimakan kurang tepat kemungkinan dapat berdampak pada kekurangan berat badan atau indeks massa tubuh dibawah angka normal.

Penelitian mengenai aktivitas sedentari pernah dilakukan di Indonesia salah satunya yaitu yang dilakukan oleh Rahmadani A, Indriasari R dan Yustini pada tahun 2014. Penelitian tersebut membahas mengenai hubungan aktivitas sedentari dengan kejadian overweight pada remaja di SMA Katolik Cendrawasih Makassar, dimana dari hasil akhir yang didapatkan menunjukkan bahwa ada korelasi antara aktivitas sedentari dengan kejadian overweight / kelebihan berat badan (Rahmadani et al., 2014).

Selain perilaku sedentari, durasi tidur juga dapat mempengaruhi body mass index seseorang. Durasi tidur pendek dapat menyebabkan terjadinya perubahan asupan energi individu (Chapman et al., 2012). Asupan makan akan berpengaruh terhadap berat badan dan menyebabkan perubahan IMT (Dewi, 2013). Remaja adalah tempo waktu transisi antara kanak-kanak menuju dewasa. Dalam masa peralihan ini tentunya diiringi perubahan jadwal dan aktivitas kegiatan. Beberapa 
diantaranya jadwal disekolah yang mulai padat. Beberapa remaja bahkan ada yang sudah mulai bekerja. Di satu sisi lingkungan pergaulan yang semakin luas, memicu kebiasaan berkeliling hingga larut malam. Selain itu mudahnya datang rasa jenuh dan bosan, membuat remaja suka mencari hiburan. Salah satunya menyaksikan tayangan televisi, dan tentunya bila sudah di depan layar kaca, akan menghabiskan waktu hingga berjam-jam hingga larut malam sehingga durasi tidur menjadi berkurang.

Orang yang tidur kurang dari 7 jam per hari memiliki resiko mendapatkan body mass index yang lebih besar dari pada orang yang tidur lebih lama karena obesitas erat kaitannya dengan sekresi hormone ghrelin dan leptin yang terdapat dalam sirkulasi darah. Ghrelin dihasilkan oleh saluran pencernaan yang berperan untuk meningkatkan nafsu makan, sedangkan leptin bertanggung jawab untuk memberikan sinyal ke otak ketika kenyang. Ketika seseorang memiliki waktu tidur yang kurang akan meningkatkan kadar ghrelin dan menurunkan kadar leptin, yang artinya rasa lapar akan terus terangsang dan meningkat (Septiana \& Irwanto, 2017).

Penelitian mengenai hubungan antara durasi tidur dan kualitas tidur dengan indeks massa tubuh dalam besar sampel dewasa muda di Universitas Zagreb Krowasia menunjukkan terdapat hubungan dimana durasi tidur yang singkat dan kualitas tidur yang buruk akan meningkatkan indeks massa tubuh (Krističević et al., 2018). Di Amerika Serikat terdapat penelitian mengenai kualitas tidur dengan indeks massa tubuh pada mahasiswa di Amerika menunjukkan 51 persen memiliki kualitas tidur yang buruk dan termasuk kategori obesitas (Perla A. Vargas, Melissa Flores, 2014). Obesitas yang menetap sejak masa anak-anak sampai dewasa memicu terjadinya hipertensi dan penyakit jantung iskemik. Oleh karena itu, obesitas menjadi masalah kesehatan pada masyarakat (Hassink, 2003).

Obesitas adalah penumpukkan lemak yang tidak normal atau berlebihan di dalam tubuh. Kondisi ini jika dibiarkan terus menerus dapat mempengaruhi kesehatan penderitanya. Kondisi ini tidak hanya berdampak pada penampilan fisik penderitanya, tetapi juga meningkatkan risiko dalam kesehatan seperti penyakit jantung, diabetes, dan tekanan darah tinggi (Bays et al., 2007).

\section{METODE}

\section{Metode dan Desain}

Metode yang digunakan dalam penelitian ini adalah metode korelasional. Penelitian korelasional adalah Penelitian yang dirancang untuk menentukan tingkat hubungan variabelvariabel yang berbeda dalam suatu populasi. Perbedaan yang utama dengan metode lain adalah adanya usaha untuk menaksir hubungan dan bukan sekedar deskripsi (Umar, 2005). Bagian ini menjelaskan mengenai metode dan desain yang digunakan dalam penelitian.

Adapun penggunaan desain penelitian yaitu menggunakan desain Explanatory dengan jenis metode multiple correlation. Desain Explanatory pada kenyataannya, desain ini dapat dikelompokkan menjadi dua jenis yaitu hubungaan sederhana simple association (Creswell,2008) atau korelasi bivariat dan hubungan lebih dari dua variabel (multiple correlation). Analisis statistik multiple correlation merupakan metode statistik yang memungkinkan kita melakukan penelitian terhadap lebih dari dua variabel secara bersamaan. Dengan menggunakan teknik analisis ini maka kita dapat menganalisis pengaruh beberapa variable terhadap variabelvariable lainnya dalam waktu yang bersamaan.

\section{Partisipan}

Partisipan dalam penelitian ini adalah 36 siswa SMA Negeri 3 Ciamis. Teknik pemilihan sampel dalam penelitian ini yaitu teknik simple random sampling pada siswa SMA Negeri 3 Ciamis. Menurut Sugiyono (2015) teknik simple random sampling adalah teknik pengambilan sampel dari anggota populasi yang dilakukan secara acak tanpa memperhatikan strata yang ada dalam populasi itu. Jadi, dalam teknik simple random sampling ini memungkinkan setiap unit 
sampling sebagai unsur populasi memperoleh peluang yang sama untuk menjadi sampel.

\section{Instrumen}

Instrumen pengumpulan data yang digunakan dalam penelitian ini adalah alat ActivPal untuk mengukur durasi tidur dan perilaku sedentari. Sedangkan instrumen penelitian untuk mengukur body mass index adalah dengan mengukur Tinggi Badan (TB) menggunakan alat stadiometer dan Berat Badan (BB) menggunakan alat timbangan berat badan dengan satuan kilogram.

\section{Analisis Data}

Analisis data dilaksanakan dengan menggunakan program Statistical Product and Service Solution (SPSS) for Windows versi 24.0 . Sebelum dilakukan analisa data, maka perlu dilakukan uji asumsi terlebih dahulu, seperti yang dijabarkan oleh (Riduwan \& Sunarto). Adapun uji asumsi dalam penelitian ini adalah uji normalitas, uji linearitas, uji korelasi pearson produst moment, dan uji regresi linear multiples.

\section{HASIL}

\section{Durasi Tidur}

Pengukuran durasi tidur, data diperoleh dengan pemasangan alat ActivPAL pada siswa SMA N 3 Ciamis. Hasil klasifikasi menjadi delapan, yaitu: (1) 6-7 jam, (2) 7-8 jam, (3) 8-9 jam, (4) 910 jam (5) 10-11 jam, (6) 11-12 jam, (7) 12-13 jam, (8) 13-14 jam. Data hasil alat ActivPAL sebagai berikut:

Tabel 1. Distribusi Durasi Tidur

\begin{tabular}{cccc}
\hline No & Kategori & \multicolumn{2}{c}{ Frekuensi } \\
\cline { 3 - 4 } & & F & F\% \\
\hline 1. & $6-7$ jam & 5 & $13,9 \%$ \\
2. & $7-8$ jam & 9 & $25 \%$ \\
3. & $8-9$ jam & 10 & $27,8 \%$ \\
4. & $9-10$ jam & 8 & $22,2 \%$ \\
5. & $10-11$ jam & 3 & $8,3 \%$ \\
6. & $11-12$ jam & 1 & $2,8 \%$ \\
7. & $12-13$ jam & 0 & $0 \%$ \\
8. & $13-14$ jam & 0 & $0 \%$ \\
\hline & JUMLAH & 36 & $100 \%$ \\
\hline
\end{tabular}

Berdasarkan tabel 1 tersebut di atas, dari 36 siswa $(100 \%)$ terdapat 5 siswa $(13,9 \%)$ dalam kategori durasi tidur 6-7 jam, 9 siswa
(25\%) dalam kategori durasi tidur 7-8 jam, 10 siswa $(27,8 \%)$ dalam kategori durasi tidur 8-9 jam, 8 siswa $(22,2 \%)$ dalam kategori durasi tidur 9-10 jam, 3 siswa (8,3\%) dalam kategori durasi tidur 10-11 jam, 1 siswa (2,8\%) dalam kategori durasi tidur 11-12 jam, 0 siswa $(0 \%)$ dalam kategori durasi tidur12-13 jam, dan tidak ada siswa dalam kategori durasi tidur 13-14 jam.

\section{Perilaku Sedentari}

Pengukuran perilaku sedentari diperoleh dari pemasangan alat ActivPAL pada siswa SMA N 3 Ciamis. Hasil klasifikasi menjadi tujuh, yaitu: (1) 6-7 jam, (2) 7-8 jam, (3) 8-9 jam, (4) 9-10 jam (5) 10-11 jam, (6) 11-12 jam, (7) 12-13 jam..

Tabel 2. Distribusi Perilaku Sedentari

\begin{tabular}{cccc}
\hline No & Kategori & \multicolumn{2}{c}{ Frekuensi } \\
\cline { 3 - 4 } & & $\mathrm{F}$ & $\mathrm{F} \%$ \\
\hline 1. & $6-7$ jam & 0 & $0 \%$ \\
2. & $7-8 \mathrm{jam}$ & 2 & $5,6 \%$ \\
3. & $8-9 \mathrm{jam}$ & 2 & $5,6 \%$ \\
4. & $9-10 \mathrm{jam}$ & 8 & $22,2 \%$ \\
5. & $10-11$ jam & 14 & $38,9 \%$ \\
6. & $11-12 \mathrm{jam}$ & 6 & $16,7 \%$ \\
7. & $12-13 \mathrm{jam}$ & 2 & $5,6 \%$ \\
8. & $13-14 \mathrm{jam}$ & 2 & $5,6 \%$ \\
\hline & JUMLAH & 36 & $100 \%$ \\
\hline
\end{tabular}

Berdasarkan data pada tabel 2, dari 36 siswa (100 \%), tidak terdapat siswa dalam kategori perilaku sedentari 6-7 jam, 2 siswa $(5,6 \%)$ dalam kategori perilaku sedentari 7-8 jam, 2 siswa $(5,6 \%)$ dalam kategori perilaku sedentari 8-9 jam, 8 siswa $(22,2 \%)$ dalam kategori perilaku sedentari 9-10 jam, 14 siswa $(38,9 \%)$ dalam kategori perilaku sedentari 10-11 jam, 6 siswa $(16,7 \%)$ dalam kategori perilaku sedentari 11-12 jam, 2 siswa $(5,6 \%)$ dalam kategori perilaku sedentari 12-13 jam, 2 siswa $(5,6 \%)$ dalam kategori perilaku sedentari 13-14 jam.

\section{Body Mass Index}

Pengukuran body mass index diperoleh dari data jenis kelamin, pengukuran berat badan, dan tinggi badan. Data hasil tersebut di klasifikasikan menurut klasifikasi Body Mass 
Index Calculator. Data hasil body mass index adalah sebagai berikut:

Tabel 3 Distribusi Tingkat Body Mass Index

\begin{tabular}{cccc}
\hline No & Kategori & \multicolumn{2}{c}{ Frekuensi } \\
\cline { 3 - 4 } & & $\mathrm{F}$ & $\mathrm{F} \%$ \\
\hline 1. & Kurus (Under & 4 & $11,1 \%$ \\
weight) & & \\
2. & Normal (Healty & 22 & $61,1 \%$ \\
weight) & & \\
3. & Kegemukan (Over & 9 & $25 \%$ \\
4. & (weight) & & \\
5. Obesitas Tingkat 1 & 1 & $2,8 \%$ \\
6. Obesitas Tingkat 2 & 0 & $0 \%$ \\
\hline & Obesitas Tingkat 3 & 0 & $0 \%$ \\
\hline
\end{tabular}

Berdasarkan tabel 3 diketahui, dari 36 siswa $(100 \%)$ terdapat 4 siswa $(11,1 \%)$ dalam kategori kurus, 22 siswa $(61,1 \%)$ dalam kategori berat badan normal, 9 siswa (25\%) dalam kategori kegemukan, 1 siswa $(2,8 \%)$ dalam kategori obesitas I, dan tidak ada siswa dalam kategori obesitas II dan III.

Tabel 4. Hasil Uji Korelasi Product Moment

\begin{tabular}{llc}
\hline & \multicolumn{2}{c}{ Correlations } \\
\hline Durasi & Pearson Correlation & BMI \\
\cline { 2 - 3 } Tidur & Sig. (2-tailed) &,- 264 \\
\cline { 2 - 3 } & $\mathrm{N}$ &, 120 \\
\hline Perilaku & Pearson Correlation &, 008 \\
\cline { 2 - 3 } Sedentari & Sig. (2-tailed) &, 963 \\
\cline { 2 - 3 } & $\mathrm{N}$ & 36 \\
\hline
\end{tabular}

Berdasarkan table 4 diketahui bahwa tidak ada hubungan yang signifikan antara durasi tidur dengan BMI ( $p>0.05$ ). Demikian juga dengan variable perilaku sedentary tidak ada hubungan yang signifikan dengan BMI ( $p$ > 0.05).

\section{PEMBAHASAN}

Berdasarkan hasil pengolahan dan analisis data bahwa tidak ada hubungan yang signifikan antara durasi tidur dan perilaku sedentary dengan body mass index (BMI). Jika dilihat dari nilai pearson correlation dengan tanda negative (-) menunjukan adanya hubungan terbalik antara durasi tidur dengan BMI. Artinya semakin meningkatnya durasi tidur, maka body mass index semakin rendah. Namun demikian korelasi yang terjadi tidak signifikan.

Beberapa penelitian mengungkap mengenai adanya hubungan antara durasi tidur dengan BMI (Hasler et al., 2004; Storfer-Isser et al., 2012), tetapi penelitian dengan menggunakan instrument serupa (accelerometer) menunjukkan hasil yang sama bahwa tidak ditemukan waktu tidur dapat memprediksi BMI (Lauderdale et al., 2009).

Ketidakseimbangan antara asupan kalori dan aktivitas fisik merupakan faktor yang berpengaruh terhadap obesitas, dimana obesitas terkait dengan body mass index (Hill et al., 2003). Faktor lingkungan dan perilaku menjadi faktor lain yang dipercaya menjadi faktor yang berpengaruh terhadap status body mass index (Bawazeer et al., 2009; Vargas et al., 2014). Jumlah waktu tidur yang kurang akan menyebabkan terganggunya proses metabolime tubuh. Gangguan metabolisme tubuh yang terjadi dalam kurun waktu lama dapat menyebabkan obesitas yang pada akhirnya akan berpengaruh juga terhadap body mass index (Galgani \& Ravussin, 2008).

Perilaku sedentari merupakan segala jenis aktivitas diluar waktu tidur, dalam posisi duduk atau berbaring yang tidak memerlukan banyak energi atau bahkan sangat sedikit energi dengan kata lain jika seseorang memiliki perilaku sedentari yang tinggi berarti dia tidak banyak bergerak. Orang yang kurang bergerak atau kurang aktif secara fisik cenderung memiliki physical self concept yang juga kurang (Ermawan et al., 2019).

Remaja yang kurang aktif secara fisik beresiko mengalami kelebihan berat badan. Hal ini terjadi karena ketidakseimbangan proses metabolisme kalori. Kalori yang masuk ke dalam tubuh dalam bentuk makanan yang kita makan akan diolah/dibakar dengan menggunakan energi yang dihasilkan dari aktivitas fisik. Jika seseorang tidak melakukan aktivitas fisik dengan intensitas tertentu, maka 
dia tidak memiliki cukup energi untuk membakar kalori yang ada dalam tubuhnya. Kalori yang terbakar lama kelamaan akan menumpuk dan akhirnya menyebabkan bertambahnya berat badan pada seseorang. (Speakman \& Selman, 2003).

Body mass index adalah metrik antropometri yang saat ini masih digunakan untuk menafirkan indeks kegemukan seseorang (Nuttall, 2015). Selain rentang usia dan jenis kelamin, body mass index menjadi faktor yang berhubungan dengan tingkat kebugaran jasmani pada lansia (Oktriani et al., 2020). Untuk mendapatkan body mass index yang ideal, seseorang tidak hanya cukup menjaga asupan gizi yang masuk ke dalam tubuhnya, akan tetapi harus memiliki gaya hidup aktif. Gaya hidup aktif ini bisa diimplementasikan dengan perilaku sedentari yang rendah dengan cara melakukan aktivitas fisik dengan intensitas moderate dan memiliki waktu istirahat yang cukup. Aktivitas fisik dengan intensitas moderate berfungsi untuk menjaga keseimbangan kalori yang masuk dan keluar dalam sistem metabolisme tubuh (Moore et al., 2014).

Durasi tidur dalam dosis yang cukup diperlukan tubuh untuk proses recovery dan menjadi bagian dari sistem metabolisme tubuh (Spaeth et al., 2015). Tubuh akan meregenerasi atau mengganti sel-sel yang rusak pada waktu tidur karena tubuh beristirahat pada saat itu. Dengan kata lain, tidur dalam durasi yang pas dan berkualitas diperlukan tubuh guna bisa memaksimalkan proses metabolisme tubuh yang efektif yang pada akhirnya akan mencegah peningkatan body mass index (Cappuccio et al., 2008)

\section{KESIMPULAN}

Berdasarkan hasil penelitian dan pembahasan yang telah dikemukakan tentang hubungan durasi tidur dan perilaku sedentari dengan body mass index, maka diperoleh kesimpulan sebagai berikut:

1. Tidak terdapat hubungan yang signifikan antara durasi tidur dengan body mass index pada siswa SMA Negeri 3 Ciamis.
2. Tidak terdapat hubungan yang signifikan antara perilaku sedentari dengan body mass index pada siswa SMA Negeri 3 Ciamis.

\section{UCAPAN TERIMA KASIH}

Penulis mengucapkan terima kasih kepada Kepala Sekolah SMAN 3 Ciamis yang memberikan kesempatan kepada peneliti sehingga peneliti bisa melakukan penelitian di SMAN 3 Ciamis.

\section{REFERENSI}

\section{Artikel Jurnal}

Bays, H E, R H Chapman, S Grandy, and Investigators Group. 2007. "The Relationship of Body Mass Index to Diabetes Mellitus, Hypertension and Dyslipidaemia: Comparison of Data from Two National Surveys." (May): $737-47$.

Bawazeer, N. M., Al-Daghri, N. M., Valsamakis, G., Al-Rubeaan, K. A., Sabico, S. L. B., Huang, T. T. K., Mastorakos, G. P., \& Kumar, S. (2009). Sleep duration and quality associated with obesity among Arab children. Obesity, 17(12), 2251-2253. https://doi.org/10.1038/oby.2009.169

Cappuccio, F. P., Taggart, F. M., Kandala, N. B., Currie, A., Peile, E., Stranges, S., \& Miller, M. A. (2008). Meta-analysis of short sleep duration and obesity in children and adults. Sleep. https://doi.org/10.1093/sleep/31.5.619

Chapman, D. P., Wheaton, A. G., Perry, G. S., Sturgis, S. L., Strine, T. W., \& Croft, J. B. (2012). Household Demographics and Perceived Insufficient Sleep Among US Adults Daniel. J Community Health, 176.

Dinkes Jabar. (2017). Profile Kesehatan Provinsi Jawa Barat 2017. In Jawa Barat, Dinas Kesehatan.

Ermawan, I., Jajat, \& Sutisna, N. (2019). Physical Self-Concept dan Body Mass Index: Hubungan dan Perbedaan berdasarkan Gender. JTIKOR-Jurnal Terapan Ilmu Keolahragaan, 4(2), 127-132.

Galgani, J., \& Ravussin, E. (2008). Energy metabolism, fuel selection and body weight 
regulation. In International Journal of Obesity. https://doi.org/10.1038/ijo.2008.246

Hasler, G., Buysse, D. J., Klaghofer, R., Gamma, A., Ajdacic, V., Eich, D., Rössler, W., \& Angst, J. (2004). The association between short sleep duration and obesity in young adults: A 13-year prospective study. Sleep, 27(4), 661-666. https://doi.org/10.1093/sleep/27.4.661

Hill, J. O., Wyatt, H. R., Reed, G. W., \& Peters, J. C. (2003). Obesity and the environment: Where do we go from here? Science, 299(5608), 853-855. https://doi.org/10.1126/science. 1079857

Krističević, T., Štefan, L., \& Sporiš, G. (2018). The Associations between Sleep Duration and Sleep Quality with Body-Mass Index in a Large Sample of Young Adults. International Journal of Environmental Research and Public Health, 15(4).

Lauderdale, D. S., Knutson, K. L., Rathouz, P. J., Yan, L. L., Hulley, S. B., \& Liu, K. (2009). Cross-sectional and longitudinal associations between objectively measured sleep duration and body mass index. American Journal of Epidemiology, 170(7), 805-813.

https://doi.org/10.1093/aje/kwp230

Moore, S. C., Matthews, C. E., Sampson, J. N., Stolzenberg-Solomon, R. Z., Zheng, W., Cai, Q., Tan, Y. T., Chow, W. H., Ji, B. T., Liu, D. K., Xiao, Q., Boca, S. M., Leitzmann, M. F., Yang, G., Xiang, Y. B., Sinha, R., Shu, X. O., \& Cross, A. J. (2014). Human metabolic correlates of body mass index. Metabolomics. https://doi.org/10.1007/s11306-0130574-1

Nuttall, F. Q. (2015). Body mass index: Obesity, BMI, and health: A critical review. In Nutrition Today. https://doi.org/10.1097/NT.0000000000 000092

Oktriani, S., Kusmaedi, N., Daniel Ray, H. R., \& Setiawan, A. (2020). Perbedaan Jenis Kelamin, Usia, dan Body Mass Index (BMI) Hubungannya dengan Kebugaran Jasmani Lanjut Usia. Jurnal Terapan Ilmu Keolahragaan, $5(1)$, $28-40$. https://doi.org/10.17509/jtikor.v5i1.2489 5

Paramitha, A. I. (2013). Hubungan Pola Makan Anak, Aktivitas Fisik Anak, dan Status Ekonomi Orang Tua dengan Obesitas Anak di Sekolah Dasar Kecamatan Pontianak Selatan. Fakultas Kedokteran, Universitas Tanjugpura.

Perla A. Vargas, Melissa Flores, E. R. (2014). Sleep Quality and Body MMass Index in College Student: The Role of Sleep Disturbance. National Institutes Health Public Access, 62(8): 534.

Rahmadani, A., Indiasari, R., \& Yustini. (2014). Hubungan Aktivitas Sedentaridengan Kejadian Overweight pada Remaja di SMA Katolik Cendrawasih Makasar. Fakultas Kesehatan Masyarakat, Universitas Hasanudin, 1-8.

Spaeth, A. M., Dinges, D. F., \& Goel, N. (2015). Resting metabolic rate varies by race and by sleep duration. Obesity. https://doi.org/10.1002/oby.21198

Speakman, J. R., \& Selman, C. (2003). Physical activity and resting metabolic rate. Proceedings of the Nutrition Society. https://doi.org/10.1079/pns2003282

Storfer-Isser, A., Patel, S. R., Babineau, D. C., \& Redline, S. (2012). Relation between sleep duration and BMI varies by age and sex in youth age 8-19. Pediatric Obesity, 7(1), 5364. https://doi.org/10.1111/j.20476310.2011.00008.x

Sugiyono. (2015). Metode Penelitian Pendidikan Pendekatan Kuantitatif, Kualitatif, dan R\&D.

Vargas, P. A., Flores, M., \& Robles, E. (2014). Sleep quality and body mass index in college students: The role of sleep disturbances. Journal of American College Health, 62(8), 534-541. https://doi.org/10.1080/07448481.2014.9 33344

\section{Buku}

Creswell, John W. (2008) Educational Research. Planing, Conducting and Evaluating 
Qualitative Approaches. London. Sage Publication.

Creswell, John W. 2012. Research Design

Pendekatan Kualitatif, Kuantitatif, dan

Mixed. Yogyakarta: Pustaka Pelajar.

Dinkes Jabar. (2017). Profile Kesehatan

Provinsi Jawa Barat 2017. In Jawa

Barat, Dinas Kesehatan. Kementrian

Pendidikan dan Kebudayaan. (2014)

Pendidikan Jasmani Olahraga dan

Kesehatan. Jakarta: Kemendikbud.

Husein Umar. (2005), Metode Penelitian Untuk

Tesis Dan Bisnis, Jakarta: Grafindo

Persada

Meredith C. Exercise and fitness. In : Rickert

$\mathrm{V}$, editor. Adolescent nutrition

assesment and management. New

York: Chapman \& Hall ; 1996. p.

2541

Sugiyono. (2015). Metode Penelitian Pendidikan

Pendekatan Kuantitatif, Kualitatif, dan

$R \& D$. 